\title{
ВСТРЕЧАЕМОСТЬ И ЧИСЛЕННОСТЬ ФОРГУТНЫХ ИНФУЗОРИЙ (CILIOPHORA, CILIATA) У ЛОСЕЙ (ALCES ALCES L.) ЧЕЛЯБИНСКОЙ И ОМСКОЙ ПОПУЛЯЦИЙ
}

\section{OCCURRENCE AND NUMBER \\ OF INFUSORIA OF STOMACH \\ (CILIOPHORA, CILIATA) IN ELK \\ (ALCES ALCES L.) OF THE CHELYABINSK AND OMSK POPULATIONS}

T. Korchagina

Summary. The article presents original data on the number and frequency of occurrence of infusoria in different parts of the stomach of elk in the Omsk and Chelyabinsk populations. Special attention is paid to the dependence of the abundance of protozoa on their distribution in the stomach. In the course of the work, a comparative analysis of the species composition of the infusor population of pre-ventricle moose of both populations was performed using the generally accepted coefficients-the Zhakkar-Malyshev coefficient (Kj-m) and the Chekanovsky — Sorensen faunal community index (Ics). The study shows that the rumen as the main place of formation and development of communities of endobiont infusoria from all the pre - ventricles of moose hosts is of priority importance for the species composition, occurrence and abundance of individual protozoan species.

Keywords: elk, ciliate of stomach, the divisions of the stomach.

\author{
Корчагина Татьяна Александровна \\ К.б.н., доцент, ФГБОУ ВО «Омский государственный \\ педагогический университет» \\ Liberova@yandex.ru
}

Аннотация. В статье представлены оригинальные данные по численности и частоте встречаемости инфузорий разных отделов желудка лося Омской и Челябинской популяций. Особое внимание уделено зависимости величины обилия простейших от распределения их по отделам желудка. В ходе работы проведен сравнительный анализ видовых составов инфузорного населения преджелудков лосей обеих популяций с применением общепринятых коэффициентов - коэффициент Жаккара - Малышева (Kj-m) и индекс общности фаун Чекановского — Соренсена (Ics). В исследовании показано, что по видовому составу, встречаемости и численности отдельных видов простейших приоритетное значение имеет рубец как основное место формирования и развития сообществ эндобионтных инфузорий из всех преджелудков хозяев.

Ключевые слова: лось, форгутные инфузории, отделы желудка.

\section{Материа^ и методика}

Сбор материала для исследования проводился на территории Омской и Челябинской областей в период с 2002-2016 годы. В северных районах Омской и Челябинской областей из разных преджелудков 20 особей лося (по 10 особей лося из каждой популяции) было собрано 600 проб (по 30 проб из каждой особи животного-хозяина). Определение видов инфузорий проведено по определительным таблицам (Догель, 1929; Lubinsky, 1957a, 1957b, 1957c, 1958). Подсчет численности инфузорий проводился методом «калиброванной капли», т.е. считались все особи, попавшие в каплю объемом 0,1 мл при разведении пробы в фиксаторе в строгом соотношении 1:2 (Лихачев, 2004).

Для сравнения видовых составов эндобионтных инфузорий из преджелудков лосей Челябинской и Омской популяций были использованы: коэффициент Жаккара - Малышева $\left(\mathrm{K}_{j-m}\right)$ и индекс общности фаун Чеканов- 


\begin{tabular}{|l|l|l|}
\hline Группа встречаемости & Число особей (диапазон от/до) & Балл встречаемости \\
\hline редко & $9-30$ & 1 \\
\hline обычно & $31-50$ & 2 \\
\hline часто & $51-80$ & 3 \\
\hline массово & $81-100$ & 4 \\
\hline
\end{tabular}

Таблица 1. Видовой состав и встречаемость в пробах (в \% / в баллах) инфузорий в преджелудках лосей Челябинской и Омской популяций

\begin{tabular}{|c|c|c|c|c|c|c|}
\hline \multirow[b]{2}{*}{ Виды } & \multicolumn{3}{|c|}{ Челябинская область n=10 (300 проб) } & \multicolumn{3}{|c|}{$\begin{array}{l}\text { Омская область } \\
\text { n=10 (300 проб) }\end{array}$} \\
\hline & $\begin{array}{l}\text { Рубец } \\
\text { (100 про6) }\end{array}$ & $\begin{array}{l}\text { Сетка } \\
\text { (100 проб) }\end{array}$ & $\begin{array}{l}\text { Книжка } \\
\text { (100 проб) }\end{array}$ & $\begin{array}{l}\text { Рубец } \\
\text { (100 проб) }\end{array}$ & $\begin{array}{l}\text { Сетка } \\
(100 \\
\text { проб) }\end{array}$ & $\begin{array}{l}\text { Книжка } \\
\text { (100 проб) }\end{array}$ \\
\hline Entodinium bursa & $30 / 1$ & $12 / 1$ & $13 / 1$ & $11 / 1$ & - & - \\
\hline E. alces & $12 / 1$ & $10 / 1$ & - & $10 / 1$ & $21 / 1$ & - \\
\hline E. furca nanellum & $78 / 3$ & - & - & $100 / 4$ & $42 / 2$ & $21 / 1$ \\
\hline E. nanellum & $97 / 4$ & $10 / 1$ & $24 / 1$ & $9 / 1$ & - & - \\
\hline E. ovinum & $89 / 4$ & $32 / 2$ & - & $43 / 2$ & $29 / 1$ & - \\
\hline E. simplex & $54 / 3$ & $27 / 1$ & - & $35 / 2$ & $24 / 1$ & - \\
\hline E. caudatum & $27 / 1$ & - & - & $18 / 1$ & - & - \\
\hline E. simulans-dubardi & $99 / 4$ & $58 / 3$ & $37 / 2$ & $69 / 3$ & $57 / 3$ & $49 / 2$ \\
\hline E. exiguum & $86 / 4$ & - & $13 / 1$ & $79 / 3$ & $62 / 3$ & - \\
\hline E. longinucleatum & $42 / 2$ & $21 / 1$ & - & $11 / 1$ & - & - \\
\hline Diplodinium anisacanthum & $47 / 2$ & - & - & - & - & - \\
\hline D. monacanthum & $92 / 4$ & $37 / 2$ & $29 / 1$ & $58 / 3$ & - & - \\
\hline D. rangiferi & $31 / 2$ & $18 / 1$ & - & $44 / 2$ & - & - \\
\hline D. bubalidis bubalidis & $29 / 1$ & $21 / 1$ & $17 / 1$ & $25 / 1$ & - & - \\
\hline D. bubalidi sconsors & $23 / 1$ & - & - & $33 / 2$ & - & - \\
\hline Epidinium ecaudatum-ecaudatum & $100 / 4$ & $86 / 4$ & - & $73 / 3$ & $51 / 3$ & - \\
\hline Dasytricha ruminantium & $68 / 3$ & $41 / 2$ & $19 / 1$ & $41 / 2$ & $28 / 1$ & $15 / 1$ \\
\hline Всего видов & 17 & 12 & 7 & 16 & 8 & 3 \\
\hline
\end{tabular}

ского - Соренсена (IсS). Пределы $\mathrm{K}_{j-m}$ от +1 (полное сходство) до - 1 (полное различие), при $\mathrm{K}_{j-m}<0$ отмечается различие, а при $\mathrm{K}_{j-m}>0-$ сходство видовых составов сравниваемых выборок. Индекс общности фаун Чекановского - Соренсена выражается в процентах и показывает количество видов общих для двух сравниваемых выборок.

Встречаемость отдельных видов учитывали в пробах в\%, а также оценивали по 4-х бальной шкале (таблица).

\section{Результаты}

Сравнение видовых составов эндобионтных инфузорий из разных преджелудков лосей Челябинской и Омской популяций с применением коэффициента
Жаккара - Малышева $\left(\mathrm{K}_{j-m}\right)$ и индекса общности фаун Чекановского-Соренсена (Ics) показало различную степень сходства/различия видовых составов цилиат.

Несмотря на общего хозяина - лося, в большинстве сравниваемых пар не наблюдается сходства видовых составов инфузорий. Только при сравнении общих видовых составов инфузорий у хозяев из разных популяций и видовых составов инфузорий рубца наблюдается сходство. Так по коэффициенту Жаккара - Малышева $\left(\mathrm{K}_{j-m}\right)$ сходство на уровне 0,88 и индексу общности фаун Чекановского-Соренсена (Ics) на уровне 96,97\%.

При сравнении видовых составов сетки и книжки отмечено различие. Так, при сравнении видовых составов инфузорий сетки лосей Челябинской и Омской по- 
пуляций наблюдается различие по $\mathrm{K}_{j-m}$ на уровне $-0,14$, а по Ics на уровне 60\%. Уровень различия при сравнении видовых составов инфузорий из книжки лосей анализируемых популяций еще выше: по $\mathrm{K}_{j-m}=-0,5$ и по Ics $=40 \%$.

Встречаемость в пробах разных видов инфузорий у обследованных особей лосей различна и варьирует от 9\% (Entodinium nanellum в рубце лосей Омской популяции) до 100\% (Entodinium furca nanellum также в рубце лосей Омской популяции и Epidinium ecaudatumecaudatum в рубце лосей Челябинской популяции) (табл. 1).

Во всех (массово встречаемые виды) или в большинстве (часто встречаемые виды) проб из рубца лосей Челябинской популяции отмечено 9 видов, или 52,9\% от всех видов, обнаруженных в рубце. Их встречаемость варьирует от 54 до 100\% проб. Для рода Entodinium отмечено 6 видов. К часто встречаемым видам относятся: $E$. simplex - 54\% и E. furca nanellum - 78\% проб, а к массово встречаемым: E. exiguum - 86\%, E. ovinum - 89\%, E. nanellum - 97\% и E. simulans-dubardi-99\% проб. Вид Diplodinium monacanthum встречен в 92\% проб, а вид Epidinium ecaudatum-ecaudatum в 100\% проб. Вид Dasytricha ruminantium в рубце лосей Челябинской популяции встречается часто в $68 \%$ проб. К группе обычно встречаемых относятся 3 вида инфузорий, или $17,6 \%$ от всех видов, обнаруженных в рубце:Diplodinium rangiferi - 31\%, D. anisacanthum - 47\% и Entodinium longinucleatum - 42\% проб. К группе редко встречаемых относятся 5 видов инфузорий, или 29,4\% от всех видов, обнаруженных в рубце (табл. 1). Их встречаемость варьирует от 12 до $30 \%$ проб.

Во всех или в большинстве проб из рубца лосей ОМской популяции отмечено 5 видов, или 31,3\% от всех видов, обнаруженных в рубце. Для рода Entodinium отмечено 3 вида: $E$. simulans-dubardi - 69\%, $E$. simplex - 79\% и E. furca nanellum - 100\% проб. Все они относятся к группам часто и массово встречаемых видов. Также к часто встречаемым видам относятся Diplodinium monacanthum - 58\% и Epidinium ecaudatum-ecaudatum - 73\% проб. К группе обычно встречаемых относятся 5 видов, или $31,25 \%$ от всех видов, обнаруженных в рубце: Entodinium simplex - 35\%, E. ovinum-43\%, Diplodinium bubalidis consors - 33\% и D. rangiferi - 44\% проб, а также Dasytricha ruminantium - 41\% проб. К группе редко встречаемых относится 6 видов, или 37,5\% от всех видов, обнаруженных в рубце (табл. 1). Их встречаемость варьирует от 9 до 25\% проб.

Таким образом, лидерами среди видов инфузорий по встречаемости в пробах (массово и часто встречаемые) из рубца лосей Челябинской и Омской популяций являются инфузории рода Entodinium от 54 до 100\% проб и вид Epidinium ecaudatum-ecaudatum от 73 до 100\% проб. При этом, сравнение видовых составов инфузорий из рубца лосей двух популяций по встречаемости показало высокие значения различий по $\mathrm{K}_{j-m}$ на уровне -0,6и по Ics на уровне 30,3\%.

Во всех или в большинстве проб из сетки лосей Челябинской популяции отмечено 2 вида, или 16,7\% от всех видов, обнаруженных в сетке. Род Entodinium представлен видом E. simulans-dubardi, обнаруженном в 58\% проб. Вид Epidinium ecaudatum-ecaudatum отмечен в 86\% проб. К группе обычно встречаемых относится 3 вида, или 25,0\% от всех видов, обнаруженных в сетке: Entodinium ovinum - 32\%, Diplodinium monacanthum - 37\% и Dasytricha ruminantium $41 \%$ проб. К группе редко встречаемых относится 7 видов, или 58,3\% от всех видов, обнаруженных в сетке (табл. 1). Их встречаемость варьирует от 10 до 27\% проб.

В пробах из сетки лосей Омской популяции отмечено 3 вида, или 37,5\% от всех видов, обнаруженных в сетке, относящихся к часто встречаемым видам: Entodinium simulans-dubardi-57\%, E. exiguum-62\% и Epidinium ecaudatum-ecaudatum отмечен в 51\% проб. К группе обычно встречаемых относится вид E. furca nanellum42\% проб. К группе редко встречаемых относится 4 вида, или 50,0\% от всех видов, обнаруженных в сетке (табл. 1). Их встречаемость варьирует от 21 до 29\% проб.

Таким образом, лидерами среди видов инфузорий по встречаемости в пробах (массово и часто встречаемые) из сетки лосей Челябинской и Омской популяций являются, как и в рубце, виды рода Entodinium и вид Epidinium ecaudatum-ecaudatum. При этом, только у лосей Челябинской популяции отмечен массово встречаемый вид - Epidinium ecaudatum-ecaudatum, обнаруженный в 86\% проб. Большая часть видов инфузорий, обнаруженных в сетке лосей обеих популяций, по встречаемости относится к группе редко встречаемых.

Сравнение видовых составов инфузорий из сетки лосей двух популяций по встречаемости показало средние значения различия по $\mathrm{K}_{j-m}$ на уровне $-0,33$ и по Ics на уровне $50,0 \%$.

В пробах из книжки лосей Челябинской популяции большинство обнаруженных видов инфузорий относятся к группе редко встречаемых - 7 видов, или 85,7\% от общего видового состава (табл. 1). Их встречаемость варьирует от 13 до 29\% проб. И только вид E. simulansdubardi встречен в 37\% проб, т.е. относится к обычно встречаемым. 
Таблица 2. Средняя численность инфузорий (особи/мл) в преджелудках лосей Челябинской и Омской популяций

\begin{tabular}{|c|c|c|c|c|c|c|}
\hline \multirow{2}{*}{ Роды/виды } & \multicolumn{3}{|c|}{$\begin{array}{l}\text { Челябинская область } \\
\text { n=10 (300 проб) }\end{array}$} & \multicolumn{3}{|c|}{$\begin{array}{l}\text { Омская область } \\
\text { n=10 (300 проб) }\end{array}$} \\
\hline & $\begin{array}{l}\text { Рубец } \\
\text { (100 проб) }\end{array}$ & $\begin{array}{l}\text { Сетка } \\
(100 \text { проб) }\end{array}$ & $\begin{array}{l}\text { Книжка } \\
\text { (100 проб) }\end{array}$ & $\begin{array}{l}\text { Рубец } \\
\text { (100 проб) }\end{array}$ & $\begin{array}{l}\text { Сетка } \\
\text { (100 проб) }\end{array}$ & $\begin{array}{l}\text { Книжка } \\
\text { (100 проб) }\end{array}$ \\
\hline Entodinium bursa & $12,3 \pm 0,3$ & $5,7 \pm 0,5$ & $1,4 \pm 0,1$ & $7,4 \pm 0,6$ & - & - \\
\hline E. alces & $7,1 \pm 0,3$ & $2,2 \pm 0,2$ & - & $3,1 \pm 0,2$ & $1,3 \pm 0,2$ & - \\
\hline E. furca nanellum & $31,8 \pm 5,7$ & - & - & $65,2 \pm 8,3$ & $29,4 \pm 3,3$ & $2,6 \pm 0,6$ \\
\hline E. nanellum & $51,9 \pm 7,1$ & $22,5 \pm 4,1$ & $9,3 \pm 2,2$ & $1,8 \pm 0,4$ & - & - \\
\hline E. ovinum & $44,6 \pm 6,2$ & $27,6 \pm 5,3$ & - & $36,8 \pm 8,1$ & $14,1 \pm 3,6$ & - \\
\hline E. simplex & $35,2 \pm 5,9$ & $23,4 \pm 5,1$ & - & $26,4 \pm 4,2$ & $18,5 \pm 2,4$ & - \\
\hline E. caudatum & $10,3 \pm 0,1$ & - & - & $1,1 \pm 0,1$ & - & - \\
\hline E. simulans-dubardi & $54,1 \pm, 3$ & $43,2 \pm 4,9$ & $16,9 \pm 3,7$ & $40,8 \pm 5,4$ & $33,6 \pm 5,3$ & $11,8 \pm 1,3$ \\
\hline E. exiguum & $49,2 \pm 6,3$ & - & $5,7 \pm 2,9$ & $56,3 \pm 4,3$ & $12,6 \pm 2,1$ & - \\
\hline E. longinucleatum & $17,3 \pm 0,5$ & $15,2 \pm 3,1$ & - & $7,4 \pm 0,6$ & - & - \\
\hline $\begin{array}{l}\text { Общая численность } \\
\text { видов / кол-во видов }\end{array}$ & $\begin{array}{l}313,8 \pm 10,4 \\
10 \\
\end{array}$ & \begin{tabular}{|l}
$139,8 \pm 5,8$ \\
7 \\
\end{tabular} & $\begin{array}{l}33,3 \pm 4,1 \\
4\end{array}$ & $\begin{array}{l}238,9 \pm 11,9 \\
10\end{array}$ & $\begin{array}{l}125,5 \pm 6,9 \\
6\end{array}$ & $\begin{array}{l}14,4 \pm 1,9 \\
2\end{array}$ \\
\hline $\begin{array}{l}\text { Diplodinium } \\
\text { anisacanthum }\end{array}$ & $19,2 \pm 3,3$ & - & - & - & - & - \\
\hline D. monacanthum & $51,6 \pm 6,9$ & $10,1 \pm 2,3$ & $2,4 \pm 0,3$ & $33,2 \pm 0,1$ & - & - \\
\hline D. rangiferi & $29,2 \pm 5,2$ & $7,1 \pm 1,9$ & - & $14,1 \pm 1,2$ & - & - \\
\hline D. bubalidis bubalidis & $3,3 \pm 0,9$ & $2,6 \pm 0,8$ & $1,2 \pm 0,1$ & $1,6 \pm 0,3$ & - & - \\
\hline D. bubalidis consors & $4,9 \pm 1,2$ & - & - & $1,2 \pm 0,3$ & - & - \\
\hline $\begin{array}{l}\text { Общая численность } \\
\text { видов / кол-во видов }\end{array}$ & $\begin{array}{l}108,2 \pm 7,1 \\
5\end{array}$ & $\begin{array}{l}19,8 \pm 3,2 \\
3\end{array}$ & $\begin{array}{l}3,6 \pm 0,7 \\
2\end{array}$ & $\begin{array}{l}50,1 \pm 0,9 \\
4\end{array}$ & - & - \\
\hline $\begin{array}{l}\text { Epidinium ecaudatum- } \\
\text { ecaudatum }\end{array}$ & $62,7 \pm 7,5$ & $25,9 \pm 2,6$ & - & $22,6 \pm 0,2$ & $11,4 \pm 0,2$ & - \\
\hline $\begin{array}{l}\text { Dasytricha } \\
\text { ruminantium }\end{array}$ & $9,6 \pm 0,7$ & $5,2 \pm 1,1$ & $1,2 \pm 0,9$ & $14,2 \pm 0,3$ & $9,1 \pm 0,3$ & $1,4 \pm 0,3$ \\
\hline Общая численность & $494,3 \pm 6,1$ & $190,7 \pm 5,6$ & $38,1 \pm 7,1$ & $333,2 \pm 7,3$ & $130,0 \pm 4,9$ & $15,8 \pm 2,1$ \\
\hline
\end{tabular}

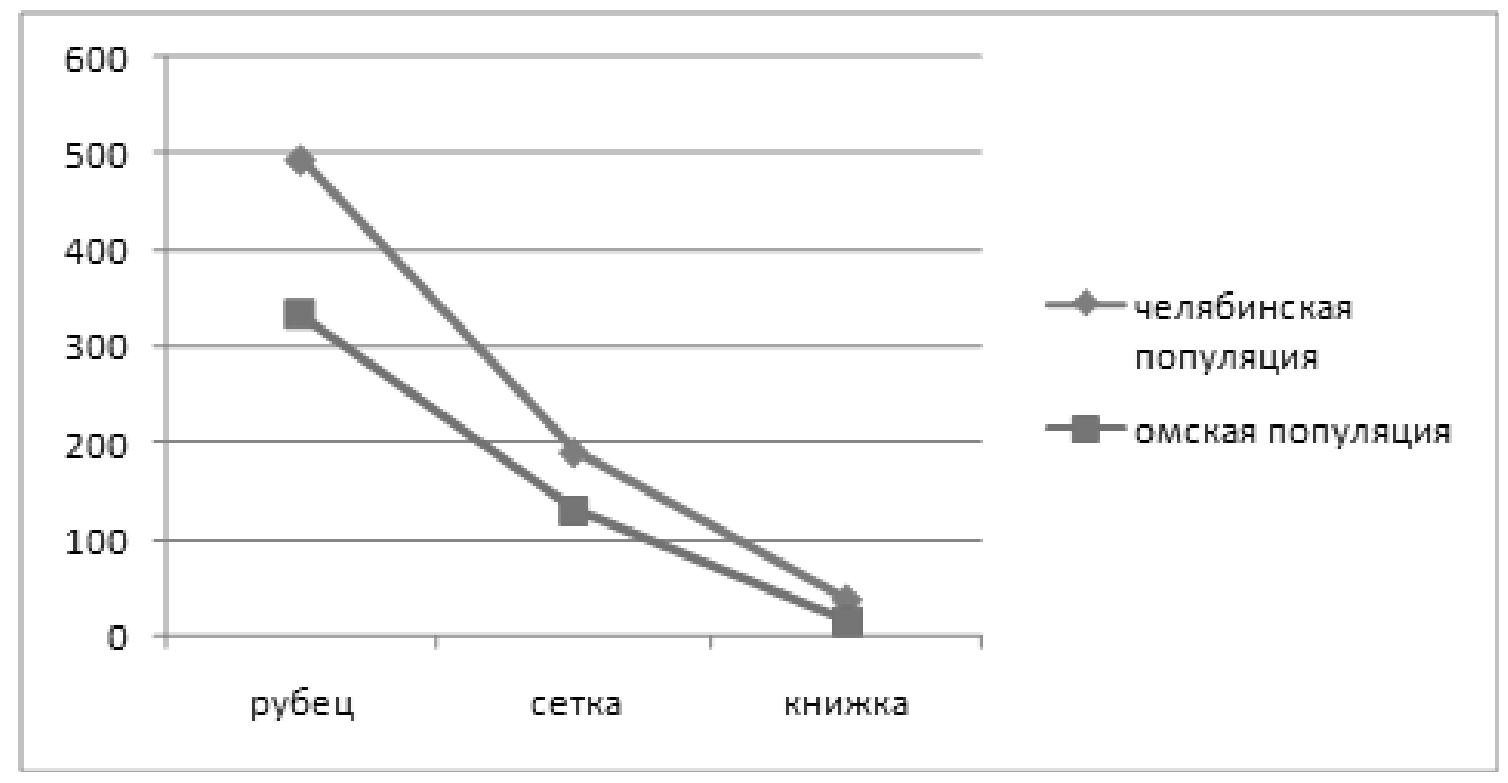

Рис. 1. Динамика численности инфузорий в преджелудках лосей Челябинской и Омской популяций 
В пробах из книжки лосей Омской популяции обнаружено всего 3 вида инфузорий, из которых 2 относятся к группе редко встречаемых (табл. 1). Их встречаемость варьирует от 15 до $21 \%$ проб. И только вид E. simulansdubardi встречен в 49\% проб, т.е. относится к группе обычно встречаемых.

Таким образом, видовой состав книжки лосей Челябинской популяции богаче, чем таковой у лосей Омской популяции. В большинстве случаев инфузории в книжке лосей обеих популяций встречаются редко. Следует отметить, что именно в книжке происходит окончательная элиминация инфузорий и в сычуг они не попадают.

В двух анализируемых популяциях лосей средняя численность инфузорий закономерно снижается от рубца к книжке у всех особей хозяина (рис. 1). Средняя численность цилиат в рубце лосей Челябинской популяции составляет 494,3 36,1 особи/мл и превышает таковую у лосей Омской популяции на 32,6\% (333,2 27,3 особи/ мл) (табл. 2).

Средняя численность цилиат в сетке лосей Челябинской популяции составляет 190,7 $\pm 5,6$ особи/мл. У лосей

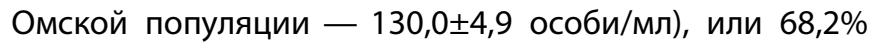
от таковой у лосей Челябинской популяции (табл. 2).

Средняя численность цилиат в книжке лосей Челябинской популяции составляет $38,1 \pm 7,1$ особи/мл и превышает таковую у лосей Омской популяции на 58,5\% (15,8 $\pm 2,1$ особи/мл) (табл. 2).

У лосей Челябинской и Омской популяций доминирующими по численности в рубце являются виды рода Entodinium. У лосей Челябинской области - 10 видов, или 58,9\% от общего видового состава и у лосей Омской области также 10 видов, или 62,5\% от общего видового состава. Из других родов в рубце лосей Челябинской популяции встречены представители родов: Diplodinium - 5 видов, и по одному виду родов Epidinium и Dasytricha. У лосей Омской популяции род Diplodinium представлен 4 видами и по одному виду из родов Epidinium и Dasytricha.

У лосей Челябинской популяции доминантными по численности являлись: Entodinium simulans-dubardi, E. nanellum, E. ovinum, E. exiguum. К группе доминантных видов по численности также можно отнести и виды Epidinium ecaudatum-ecaudatum и Diplodinium monacanthum. Все указанные 6 видов трех родов имели суммарную численность 314,1 особи/мл, или 63,5\% от общей численности всех инфузорий рубца лосей Челябинской популяции. Субдоминантными видами по численности являлись: Entodinium furca nanellum, E. simplex и Diplodinium rangiferi. Их численность в сумме составляет 96,3 особи/мл или 19,5\% от общей численности всех инфузорий рубца лосей Челябинской популяции. Остальные 8 видов инфузорий из рубца лосей Челябинской популяции имели совокупную численность 84 особи/мл, или 16,9\% от общей численности всех инфузорий рубца.

У лосей Омской популяции доминантными явились только виды рода Entodinium: E.furca nanellum, E. ovinum, E.simulans-dubardi, E. exiguum, численность которых в сумме составляет 199,1 особи/мл, или 59,8\% от общей численности всех инфузорий рубца. Субдоминантными видами являлись: Entodinium simplex, Diplodinium monacanthum и Epidinium ecaudatumecaudatum численность которых в сумме составляет 82,2 особи/мл, или $24,7 \%$ от общей численности всех инфузорий рубца лосей Омской популяции. Остальные 9 видов инфузорий рубца лосей Омской популяции дали совокупную численность 43,9 особи/мл, или 15,5\% от общей численности всех инфузорий рубца.

Таким образом, ядро видового состава инфузорной фауны рубца лосей Челябинской популяции по численности составили 6 доминантных и 3 субдоминантных вида. Ядро видового состава инфузорной фауны рубца лосей Омской популяции по численности составили 4 доминантных вида рода Entodinium и 3 вида субдоминанта трех разных родов. Следует отметить, что основу ядра доминантных по численности видов у обеих популяций лосей составляют практически одни и те же виды инфузорий. Общими доминантными видами инфузорий рубца лосей обеих популяций Entodinium simulans-dubardi, E. nanellum, E. ovinum, E. exiguum, а как общий субдоминантный вид отмечен Entodinium simplex. У лосей Челябинской популяции доминантными также являлись: Epidinium ecaudatum-ecaudatum и Diplodinium monacanthum. Стоит отметить, что в рубце лосей Омской популяции они являются субдоминантными видами. И наоборот, вид Entodinium furca nanellum для рубца лосей Омской популяции являлся доминантным видом, тогда как у лосей Челябинской популяции был отмечен как субдоминантный вид.

Сравнение видовых составов доминантных и субдоминантных видов инфузорий рубца лосей Челябинской и Омской популяций по коэффициенту Жаккара - Малышева $\left(\mathrm{K}_{j-m}\right)$ и индексу общности фаун Чекановского-Соренсена (Ics) показало, что наблюдается высокая степень сходства. Так, по $\mathrm{K}_{j-m}$ сходство равно 0,75, a Ics $=93,3 \%$. Именно высоким сходством видовых составов доминантных и субдоминантных видов можно объяснить приведенное выше сходство при сравнении общих видовых составов инфузорий рубца лосей обеих популяций. 
У лосей Челябинской и Омской популяций доминирующими по численности в сетке, также, как и рубце, являются виды рода Entodinium (табл. 2).

У лосей Челябинской области отмечено 7 видов, или $58,3 \%$, от общей численности всех инфузорий сетки, а лосей Омской области - 6 видов, или 75,0\% от общей численности всех инфузорий сетки. Из других родов в сетке лосей Челябинской популяции встречены представители родов: Diplodinium - 3 вида и по одному виду родов Epidinium и Dasytricha. У лосей Омской популяции не отмечены виды рода Diplodinium. Из других родов в сетке лосей Челябинской популяции встречены представители родов: Diplodinium - 3 вида и по одному виду родов Epidinium и Dasytricha. У лосей Омской популяции в сетке особи и фрагменты клеток видов рода Diplodinium не были обнаружены.

У лосей Челябинской популяции доминантным видом сетки являлся Entodinium simulans-dubardi43,2 особи/мл, или 22,7\% от общей численности инфузорий сетки. К субдоминантным видам отнесены: E. nanellum, E. ovinum, E. simplex u Epidinium ecaudatum-ecaudatum. Численность этих видов в сумме составляет 99,4 особи/мл, или $52,1 \%$ от общей численности всех инфузорий сетки лосей данной популяции. Для указанных 5 видов двух родов численность в сумме составляет 142,6 особи/мл, или 74,8\% от общей численности всех инфузорий сетки лосей Челябинской популяции. Остальные 7 видов инфузорий сетки лосей данной популяции дали совокупную численность 48,1 особи/мл, или $25,2 \%$ от общей численности всех инфузорий сетки.

Средняя численность цилиат в книжке лосей Челябинской популяции составляет $38,1 \pm 7,1$ особи/мл и превышает таковую у лосей Омской популяции на 58,5 (15,8 22,1 особи/мл) (табл. 2).

\section{Зак^ючение}

Приведенные данные о видовом составе, встречаемости и численности отдельных видов инфузорий в преджелудках лосей Челябинской и Омской популяций свидетельствуют, что именно рубец является тем преджелудком, где сообщество инфузорий развивается, т.е. испытывает первичное накопление при груминге, активное размножение для увеличения численности и элиминацию некоторых видов. Ряд видов переходят вместе с пищевыми массами в сетку, где размножения у инфузорий не отмечено и происходит элиминация некоторых видов. Окончательная элиминация особей минимального числа видов инфузорий происходит в книжке. Таким образом, в сетке и книжке происходит утилизация особей ряда видов без их размножения. В сычуге эндобионтные инфузории отсутствуют, и даже не встречены фрагменты их клеток, что характерно для всех форгутных инфузорий, обитающих в преджелудках жвачных (Dogiel, 1927; Догель, 1929; Dehority, 1996, 2005).

\section{Выво $\triangle \mathrm{b}$}

1. Видовые составы эндобионтных инфузорий из преджелудков лосей Челябинской и Омской популяций имеют сходство в рубце, но различаются в сетке и книжке.

2. Встречаемость отдельных видов инфузорий в рубце выше, чем в сетке и книжке.

3. Общая численность видов инфузорий испытывает динамику существенного снижения от рубца к книжке.

4. Данные по видовому составу, встречаемости и численности отдельных видов указывают на приоритетное значение рубца как основного места формирования и развития сообществ эндобионтных инфузорий из всех преджелудков хозяев.

\section{ЛИТЕРАТУРА}

1. Догель В. А. Простейшие — Protozoa, малоресничные инфузории — Oligotricha сем. Ophryoscolecidae. Определители по фауне СССР. — Л.: Изд-во 3ИН АН, 1929. - 158 c.

2. Корчагина Т. А., Лихачев С. Ф. Видовое разнообразие и численность эндобионтных инфузорий в разных отделах желудка лося. // Омский научный вестник. Изд-во: Омский государственный технический университет, 2006. - С. 244-246.

3. Корчагина Т. А., Лихачев С. Ф. Количественная характеристика сообществ эндобионтных инфузорий отделов желудка лося (Alces alces L., 1758) // Maтериалы III научно-практ. конф. «Актуальные проблемы биологии и методики ее преподавания в школе и в ВУЗе» — Омск: изд-во 0мГПУ, 2015.— С. 19-23.

4. Корчагина Т. А. Сравнительная характеристика инфузорной фауны рубца лосей Омской и Челябинской популяций // Современная наука: актуальные проблемы теории и практики. Серия: Естественные и технические науки,-2019,-9.—C. 14-18.

5. Корчагина Т. А., Лихачев С. Ф. Оценка относительного обилия форгутных инфузорий (Ciliophora, Ciliata) лося (Alces alces L.) Омской и Челябинской популяций. // Современная наука: актуальные проблемы теории и практики. Серия: Естественные и технические науки. —2020.-2 - C. 35-40.

6. Лихачев С. Ф. Полевые и экспериментальные исследования беспозвоночных. СПб.: Тесса, 2004.— 157 c.

7. Dehority B. A. A new family of entodiniomorph protozoa from the marsupial forestomach, with descriptions of a new genus and five new species. // J. Eucaryotic Microbiol., 1996. - P. 285-295. 
8. Dehority B. A. Effect of $\mathrm{pH}$ on viability of Entodinium caudatum, Entodinium exiguum, Epidinium caudatum, and Ophryoscolex purkynjei in vitro. // Journal of Eukaryotic Microbiology, 52, 2005.- P. 339-342.

9. Dogiel V. A. Monographie der Familie Ophryoscolecidae. // Arch. Protistenkd., 1927. 59, — P. 1-288.

10. Lubinsky G. Studies on the evolution of the Ophryoseolecidae: some evolutionary trends on the genus Entodinium // Canad. J. Zool., 1957a. 35, 1.—P. 111-133.

11. Lubinsky G. Studies on the evolution of the Ophryoscolecidae (Ciliata: Oligotricha). IL On the origin of the higher ophryosolecidae // Can. J. Zool., 1957b. 35, 1. — P. 135-140.

12. Lubinsky G. Studies on the evolution of the Ophryoscolecidae. Phylogeny of the Ophryoscolecidae based on their comparative morphology // Canad. J. Zool., 1957c. 35, 1.- P. 141-159.

13. Lubinsky G. Ophryoscolecidae (Ciliata, Entodiniomorphida) of reindeer (Rangifer tarandus L.) from Canadien Arctic. // Can. J. Zool., 1958. -pp. 819-825, 937-959.

( Корчагина Татьяна Александровна ( Liberova@yandex.ru ).
Журнал «Современная наука: актуальные проблемы теории и практики»

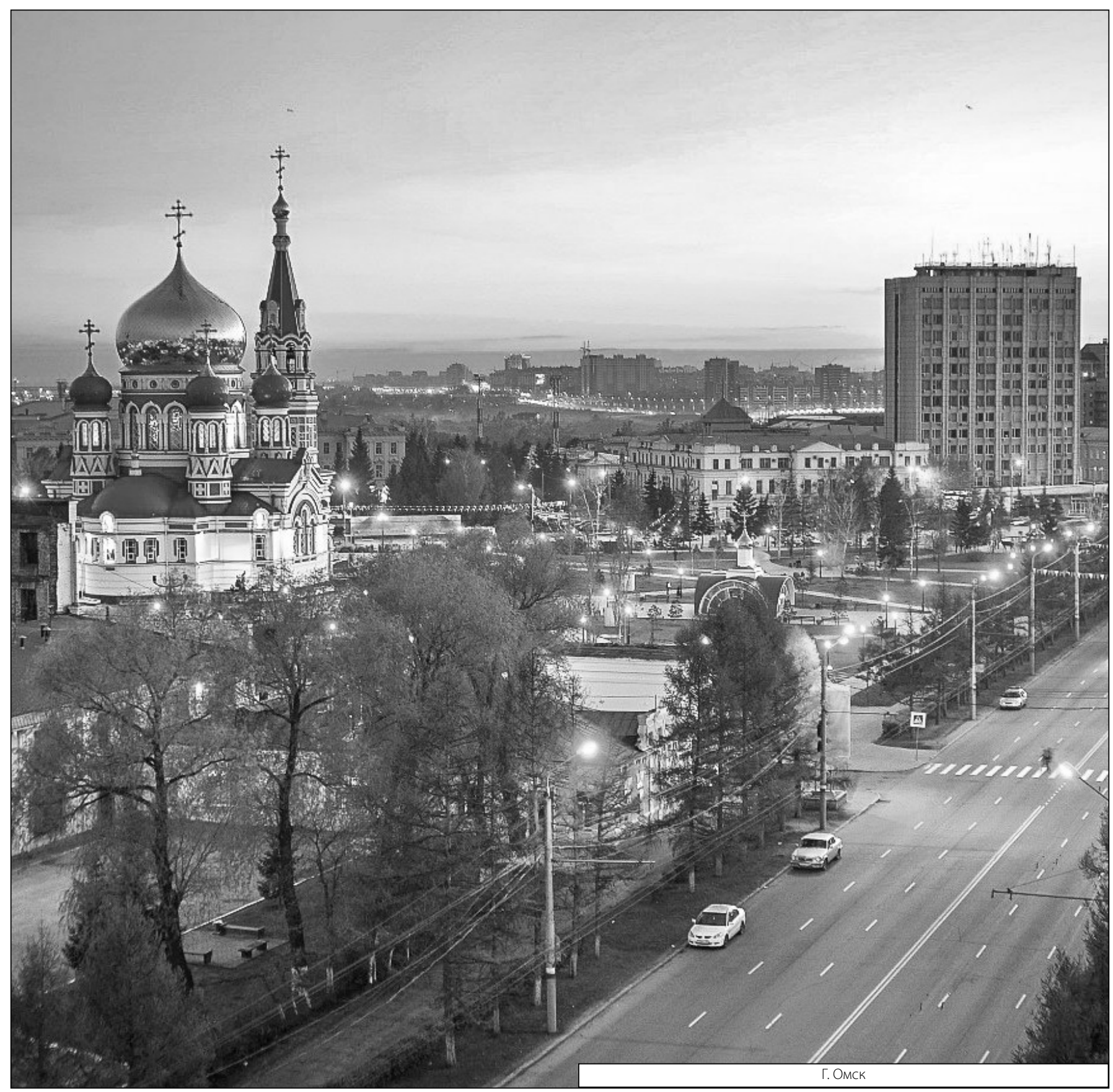

